\title{
Inflammatory Effect of Light-Emitting Diodes Curing Light Irradiation on Raw264.7 Macrophage
}

\author{
Moon-Jin Jeong ${ }^{1}$, Ki-Sung Kil ${ }^{1}$, Myoung-Hwa Lee ${ }^{1}$, Seung-Yeon Lee ${ }^{1}$, Hye-Jin Lee ${ }^{2}$, Do-Seon Lim ${ }^{3}$, and \\ Soon-Jeong Jeong ${ }^{4}+$ \\ ${ }^{1}$ Department of Oral Histology and Developmental Biology, School of Dentistry, Chosun University, Gwangju 61452, \\ 2Department of Dental Hygiene, Dong-Pusan College, Busan 48000, \\ ${ }^{3}$ Department of Dental Hygiene, Graduate School of Public Health Science, Eulji University, Seongnam 13135, \\ ${ }^{4}$ Department of Dental Hygiene, College of Health Science, Youngsan University, Yangsan 50510, Korea
}

\begin{abstract}
Background: The light-emitting diode (LED) curing light used is presumed to be safe. However, the scientific basis for this is unclear, and the safety of LED curing light is still controversial. The purpose of this study was to investigate the effect of LED curing light irradiation according to the conditions applied for the polymerization of composite resins in dental clinic on the cell viability and inflammatory response in Raw264.7 macrophages and to confirm the stability of LED curing light.

Methods: Cell viability and cell morphology of Raw264.7 macrophages treated with $100 \mathrm{ng} / \mathrm{ml}$ of lipopolysaccharide (LPS) or/and LED curing light with a wavelength of $440 \sim 490 \mathrm{~nm}$ for 20 seconds were confirmed by methylthiazolydiphenyl-tetrazolium bromide assay and microscopic observation. The production of nitric oxide $(\mathrm{NO})$ and prostaglandin $\mathrm{E}_{2}\left(\mathrm{PGE}_{2}\right)$ was confirmed by $\mathrm{NO}$ assay and $\mathrm{PG} \mathrm{E}_{2}$ enzyme-linked immunosorbent assay kit. Expression of interleukin (IL)-1 $\beta$ and tumor necrosis factor (TNF)- $\alpha$ in total RNA and protein was confirmed by reverse transcription polymerase chain reaction and Western blot analysis.

Results: The LED curing light did not affect the viability and morphology of normal Raw264.7 cells but affected the cell viability and induced cytotoxicity in the inflammation-induced Raw264.7 cells by LPS. The irradiation of the LED curing light did not progress to the inflammatory state in the inflammation-induced Raw264.7 macrophage. However, LED curing light irradiation in normal Raw264.7 cells induced an increase in NO and $\mathrm{PGE}_{2}$ production and $\mathrm{mRNA}$ and protein expression of $\mathrm{IL}-1 \beta$ and TNF- $\alpha$, indicating that it is possible to induce the inflammatory state.

Conclusion: The irradiation of LED curing light in RAW264.7 macrophage may induce an excessive inflammatory reaction and damage oral tissues , Therefore, it is necessary to limit the long-term irradiation which is inappropriate when applying LED curing light in a dental clinic.
\end{abstract}

Key Words: Inflammatory effect, Light-emitting diode, Light curing light, Macrophage, Raw264.7 cell

\section{Introduction}

The light-emitting diode (LED), introduced in the 1990s, consists of a combination of two semiconductors which effectively convert electricity into light ${ }^{1)}$. The LED has also been developed as light sources for light curing units for the polymerization of composite resins used for tooth restoration ${ }^{1,2)}$. LED light is a blue light with a wavelength of $420 \sim 600 \mathrm{~nm}$ with a semi-permanent life span of 10,000 hours or more ${ }^{3,4)}$ and is widely used in dental clinic because of its low cost and strong resistance to vibration and impact ${ }^{5,6)}$. Although the LED curing light used for polymerization of composite resins is presumed to be safe, the scientific basis for this is insufficient and unclear $^{7,8)}$. In addition, there is some evidence that it directly or indirectly affects oral tissues (including non-dental and dental), and the safety of LED curing light is still controversial $^{7,8)}$. It has also been reported that the effect of the LED curing light differs depending on the time and intensity of light irradiation and the cells and tissues 
examined $^{7-9)}$. It is therefore pertinent to explore the effects of LED curing light on non-dental and dental tissue. Macrophages overexpress pro-inflammatory mediators such as reactive oxygen species, nitric oxide (NO) and prostaglandin $\mathrm{E}_{2}\left(\mathrm{PGE}_{2}\right)$ and pro-inflammatory cytokines such as interleukin (IL)-1 $\beta$, IL-6, IL-10, and tumor necrosis factor (TNF)- $\alpha$ when exposed to toxic substances ${ }^{10,11)}$. Over-expressed pro-inflammatory mediators and pro-inflammatory cytokines play an important role in the induction of inflammatory diseases ${ }^{10-12)}$. Periodontal disease is also an inflammatory disease caused by the interaction of leukocytes such as macrophages and certain pathogenic microorganisms living in the oral cavity ${ }^{13-15)}$. Therefore, the Raw264.7 macrophage is an ideal cell line to study the effect of LED curing light in the oral cavity. The purpose of this study was to investigate the effect of LED curing light irradiation according to the conditions applied to polymerize of composite resins in dental clinics on the cell viability and inflammatory response in Raw264.7 macrophages and to confirm the stability of LED curing light.

\section{Materials and Methods}

\section{Cell culture}

The RAW264.7 macrophage were purchased from the Korean Cell Line Bank (KCLB, Seoul, Korea). The cells were stabilized and cultured in Dulbecco's modified Eagle's medium (DMEM; Gibco-BRL, Seoul, Korea) in a $\begin{array}{lllll}37^{\circ} \mathrm{C} & 5 \% & \mathrm{CO}_{2} & \text { incubator. A } 10 \% \text { fetal bovine serum }\end{array}$ (Gibco-BRL) and 1\% antibiotic-antimycotic solution (Gibco-BRL) were added to the medium. Cells were divided into control, lipopolysaccharide (LPS) only treated LPS + group, LED only irradiated LED+ group, and LPS+/LED+ group treated with LPS treatment and LED irradiation.

\section{Lipopolysaccharide treatment and light-emitting diode curing light irradiation}

The prepared cells were replaced with fresh medium, treated with $100 \mathrm{ng} / \mathrm{ml}$ of LPS or/and irradiated with LED curing light for 20 seconds according to the conditions applied for the polymerization of composite resins in dental clinics and then replaced with fresh medium. The light curing unit used in this experiment has a wavelength of $440 \sim 490 \mathrm{~nm}$ and the LED is the right source (Table 1). The treated cells were incubated for 0,24 , and 48 hours and then used for experiments.

\section{Methylthiazolydiphenyl-tetrazolium bromide assay}

The effect of LED curing light irradiation on cell viability was evaluated by methylthiazolydiphenyltetrazolium bromide (MTT) assay. Prepared cells were treated with $0.5 \mathrm{mg} / \mathrm{ml}$ of MTT (Sigma-Aldrich Chemical Co., St. Louis, MO, USA) and reacted in a dark incubator for 2 hours. After removal of MTT from the cell, the cells were treated with dimethyl sulfoxide (DMSO; SigmaAldrich Chemical Co.), and $200 \mu$ of the DMSO-treated solution was transferred to a 96-well plate, and the absorbance was read at $540 \mathrm{~nm}$ using an enzyme-linked immunosorbent assay (ELISA) reader (Molecular Devices, Sunnyvale, CA, USA) was measured.

\section{Microscopic examination}

The morphological changes of cells by LED curing light irradiation were observed with an inverted microscope (Olympus, Tokyo, Japan). Prepared cells were fixed with $2.5 \%$ glutaraldehyde (MERCK, Frankfurter, Germany) in phosphate buffered saline (PBS) ( $\mathrm{pH} \mathrm{7.4),} \mathrm{washed} \mathrm{three}$ times with PBS, and the morphology of cell was observed.

\section{Nitric oxide assay}

The changes in a pro-inflammatory mediator, NO by LED curing light irradiation were measured using NO assay kit (R\&D Systems, Minneapolis, MN, USA). The

Table 1. Light Curing Unit

\begin{tabular}{cccccc}
\hline Light source & Wave length & Exposure time & Dose of light & Company & Model no. \\
\hline LED & $440 \sim 490 \mathrm{~nm}$ & $20 \mathrm{~s}$ & $20 \mathrm{~J} / \mathrm{cm}^{2}$ & Dematec Co., Ltd., Busan, Korea & Skylight \\
\hline
\end{tabular}

LED: light-emitting diode. 
supernatants of the cells treated with the reagent according to the manufacturer's method were transferred to a 96-well plate and measured at $540 \mathrm{~nm}$ absorbance using the ELISA reader.

\section{Prostaglandin $E_{2}$ enzyme-linked immunosorbent assay}

The concentration of $\mathrm{PGE}_{2}$, which is a pro-inflammatory mediator that plays an important role in the initiation of inflammatory responses, was measured using a $\mathrm{PGE}_{2}$ ELISA kit (R\&D Systems). The supernatants of the prepared cells were treated according to the manufacturer's method and the absorbance at $490 \mathrm{~nm}$ was measured using an ELISA reader to determine the $\mathrm{PGE}_{2}$ concentration.

\section{RNA extraction and reverse transcription polymerase chain reaction analysis}

Total RNA was isolated using TRIzol reagent (Molecular Research Center Inc., Cincinnati, OH, USA) according to the manufacturer's instructions. Isolated total RNA was reverse transcribed into complementary DNA (cDNA). Specific primers (Bioneer Co., Ltd., Daejeon, Korea) were used for reverse transcription polymerase chain reaction (RT-PCR). The desired genes were amplified according to the Jeong et al. ${ }^{16)}$ and were then electrophoresed on $1.5 \%$ agarose gel. The bands were visualized by Gel-Doc System (BioRad Laboratories Inc., Hercules, CA, USA) and measured by Science Lab Image Guage (Fujifilm, Tokyo, Japan).

\section{Protein extraction and Western blot analysis}

According to the method of Jeong et al. ${ }^{16)}$, total protein was separated, the concentration of the protein was measured, prepared total protein was electrophoresed on $10 \%$ SDS-polyacrylamide gel and then western blot and immunoprecipitation were performed on specific protein. The intensity of the band detected with ECL solution (Merck Millipore, Burlington, MA, USA) was measured by Science Lab Image Guage (Fujifilm).

\section{Statistical analysis}

Using Excel 2010 statistical software (Microsoft, Redmond, WA, USA), the mean, standard deviation, p-values $\left({ }^{*} \mathrm{p}<0.05,{ }^{* *} \mathrm{p}<0.01, * * * \mathrm{p}<0.001\right)$ of the results from three replica experiments were calculated. Significant differences were analyzed using the Student's t-test.
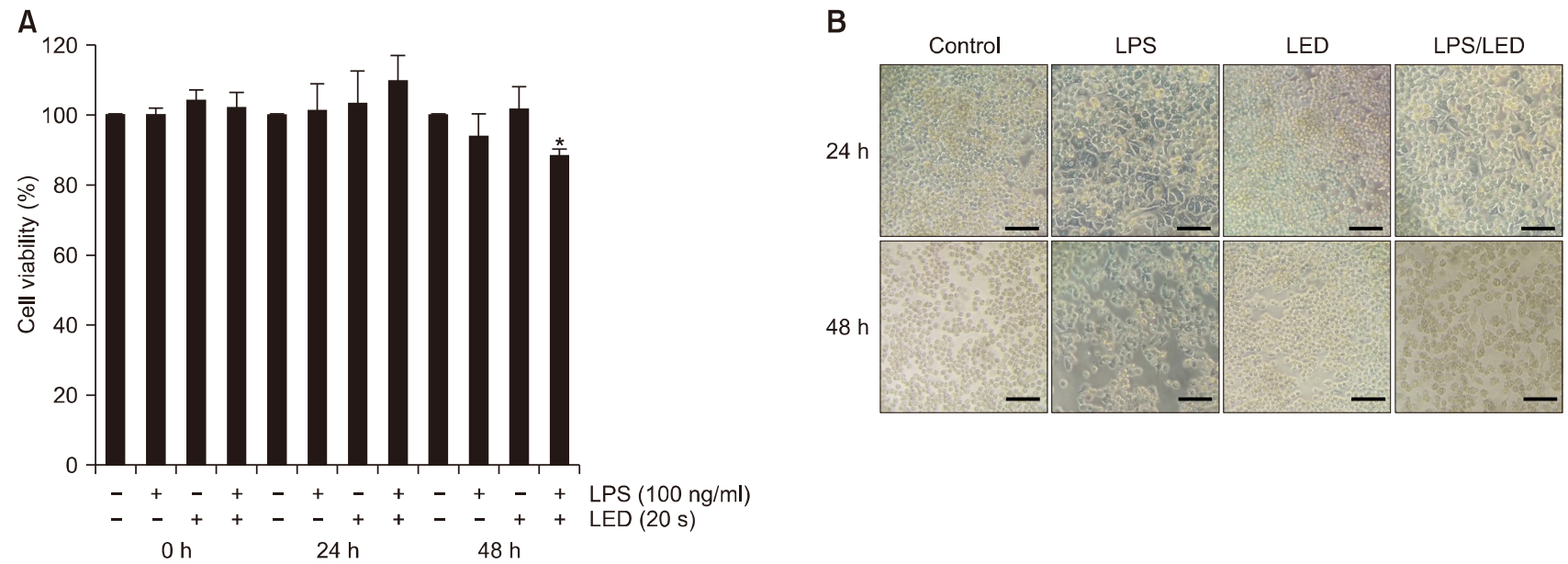

Fig. 1. Cell viability of Raw264.7 macrophages irradiated with LED curing light. (A) Cell viability of Raw264.7 macrophages treated with $100 \mathrm{ng} / \mathrm{ml}$ of LPS or/and LED curing light irradiation with wavelength of $440 \sim 490 \mathrm{~nm}$ for 20 seconds were confirmed by MTT assay. The experiment was repeated three times and performed independently, and the results were expressed as mean and standard deviation. (B) Morphological changes of prepared Raw264.7 cells were observed by inverted microscope. All scale bars indicate 60 $\mu \mathrm{m}$. LED: light-emitting diode, LPS: lipopolysaccharide, MTT: methylthiazolydiphenyl-tetrazolium bromide. $* \mathrm{p}<0.05$. 


\section{Results}

1. Cell viability of Raw264.7 macrophages irradiated with light-emitting diode curing light

Cell viability and cytotoxic effect of Raw264.7 macrophages treated with $100 \mathrm{ng} / \mathrm{ml}$ of LPS or/and LED curing light with a wavelength of $440 \sim 490 \mathrm{~nm}$ for 20 seconds of general applying the composite resin for polymerization in dental clinics were confirmed by MTT assay. There was no significant change in cell viability of all groups, except for 48 hours LPS+/LED+ group, a significant decrease was seen compared to the control $(\mathrm{p}<$ 0.05) (Fig. 1A). This suggests that although the LED curing light did not affect the cell viability and cytotoxicity of normal Raw264.7 macrophages, LPSinduced inflammation in Raw264.7 cells may decrease cell viability and may have a cytotoxic effect. Microscopic observations of Raw264.7 cells revealed that the LPS+ and LPS+/LED+ group at 24 hours and 48 hours had an extended cytoplasmic process resulting from LPS stimulation, but no change in cell morphology was observed in the LED+ group (Fig. 1B). Therefore, the microscopic observation of the Raw264.7 cell morphology showed no effect of the LED curing light.

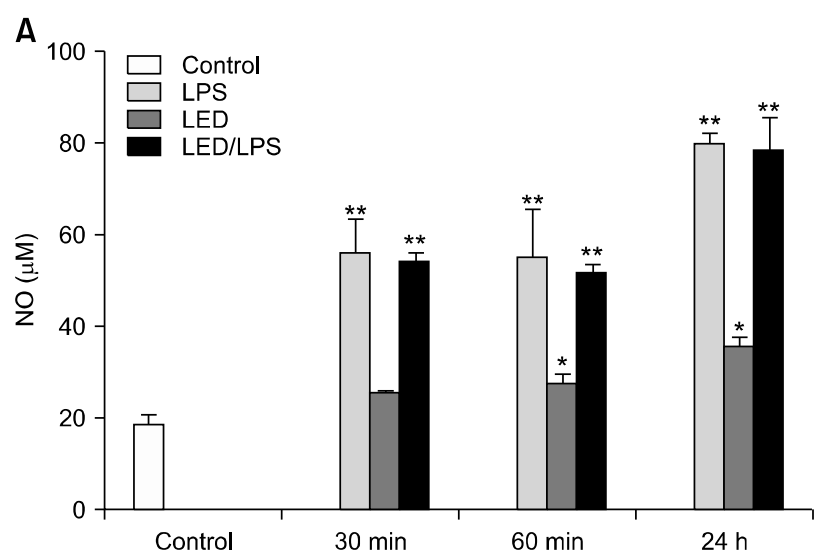

2. Nitric oxide and prostaglandin $E_{2}$ production of Raw264.7 macrophages irradiated with lightemitting diode curing light

The production of $\mathrm{NO}$ and $\mathrm{PGE}_{2}$ in the prepared Raw264.7 macrophage was confirmed by NO assay and $\mathrm{PGE}_{2}$ ELISA kit (Fig. 2). Significant increase in NO was observed in the LPS+ and LPS+/LED+ group with increasing time $(\mathrm{p}<0.01)$ and the amount of NO production in both groups was similar (Fig. 2A). The increase in NO production in both groups was thought to be due to LPS treatment and the effect of LED irradiation was not confirmed. In the case of NO of LED+ group, NO production increased with increasing time, and at 60 minutes and 24 hours, the increase was significant compared with the control group (Fig. 2A) $(\mathrm{p}<0.05)$. These results imply that LED curing light irradiation can affect the production of NO in normal Raw264.7 macrophage. $\mathrm{PGE}_{2}$ also increased significantly in LPS+ and LPS+/LED+ groups with time compared to control. The amount of $\mathrm{PGE}_{2}$ production was similar in both groups, but the value of LPS+/LED+ group was lower than that of LPS + group $(\mathrm{p}<0.05, \mathrm{p}<0.01)$ (Fig. 1B). $\mathrm{PGE}_{2}$ production in both groups was also considered to be due to LPS, and the effect of LED curing light irradiation was not confirmed. A significant increase in $\mathrm{PGE}_{2}$ was also observed in the LED+ group after 24 hours, which suggests that LED irradiation could affect the production

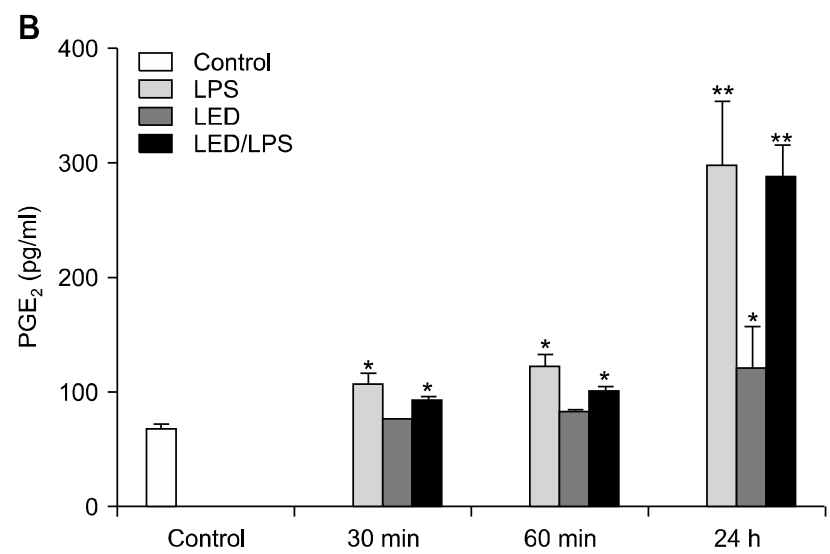

Fig. 2. $\mathrm{NO}$ and $\mathrm{PGE}_{2}$ production of Raw264.7 macrophages irradiated with LED curing light. Raw264.7 macrophage were irradiated with LED curing light for 20 seconds or/and treated with $100 \mathrm{ng} / \mathrm{ml}$ LPS. The production of NO (A) and PGE 2 (B) in the prepared Raw264.7 macrophage was confirmed by $\mathrm{NO}$ assay and $\mathrm{PGE}_{2}$ ELISA kit. All experiments were carried out three times independently and their values were expressed as mean and standard deviation. NO: nitric oxide, $\mathrm{PGE}_{2}$ : prostaglandin $\mathrm{E}_{2}$, LED: light-emitting diode, LPS: lipopolysaccharide, ELISA: enzyme-linked immunosorbent assay. $\star p<0.05$ and $\star \star p<0.01$ compared with the control group. 
of $\mathrm{PGE}_{2}$. From the above results, the irradiation of the LED curing light does not increase the inflammatory state in the LPS-induced Raw264.7 macrophage cells, however, normal Raw264.7 cells can induce an increase in NO and $\mathrm{PGE}_{2}$ production, indicating that it is possible to induce inflammation.
3. Interleukin-1 $\beta$ and tumor necrosis factor- $\alpha$ expression of Raw264.7 macrophages irradiated with light-emitting diode curing light

Total RNA and protein were extracted from Raw264.7 macrophages treated with LPS of $100 \mathrm{ng} / \mathrm{ml}$ or/and irradiated with LED curing light for 20 seconds and RT-PCR and Western blot analysis were performed on IL-1 $\beta$ and TNF- $\alpha$ (Fig. 3). In the case of LPS+ and LPS+/LED+ group, mRNA expression of IL-1 $\beta$ (Fig. 3A, 3B) and TNF- $\alpha$ (Fig. 3A, 3C) was significantly increased
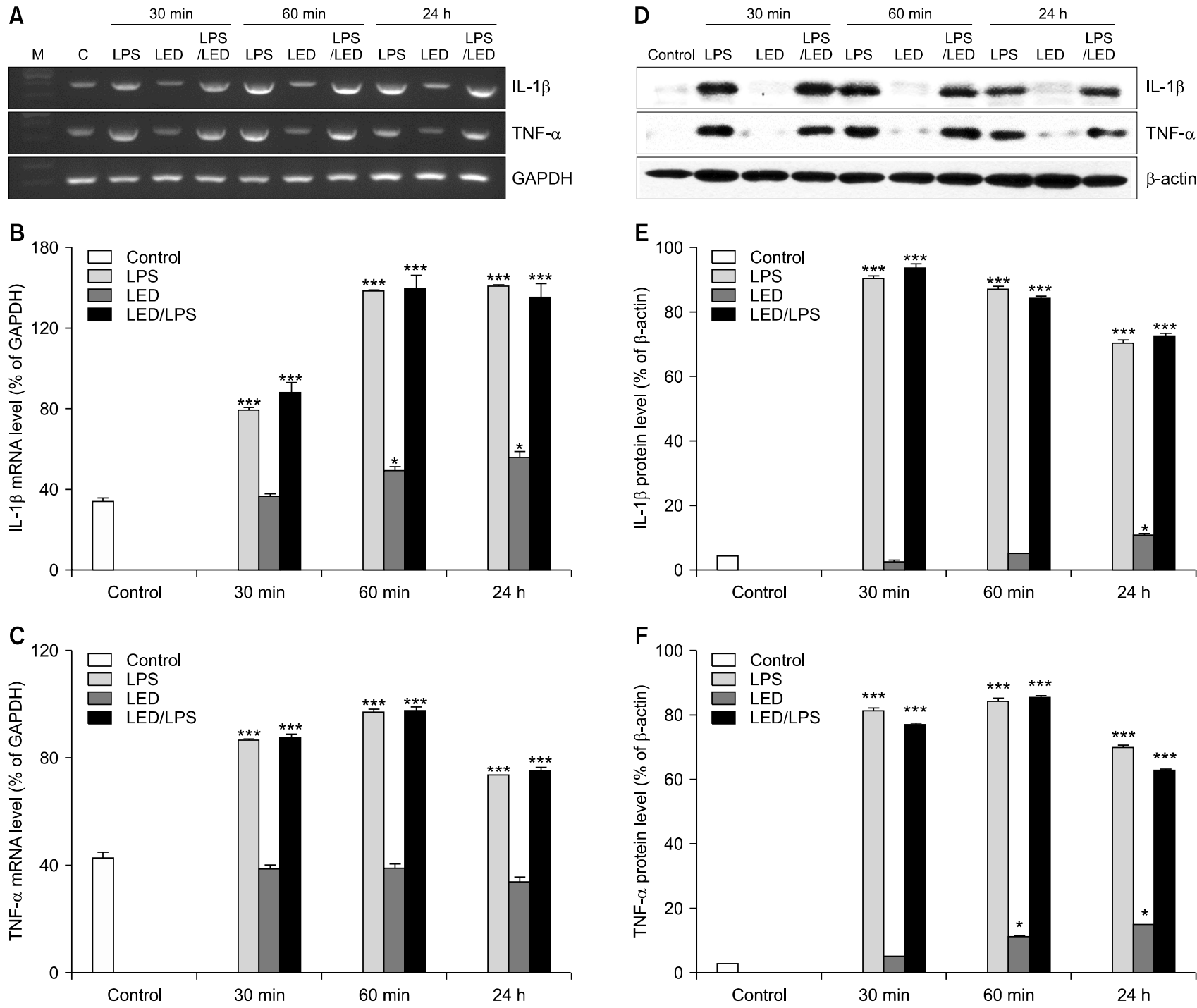

Fig. 3. IL $-1 \beta$ and TNF- $\alpha$ expression of Raw264.7 macrophages irradiated with LED curing light. Total RNA and protein were extracted from Raw264.7 macrophages treated with LPS $(100 \mathrm{ng} / \mathrm{ml})$ or/and irradiated with LED curing light for 20 seconds and RT-PCR (A C) and Western blot analysis $(D \sim F)$ of $\mathrm{IL}-1 \beta$ and TNF $-\alpha$ were performed. Values are represented the mean \pm standard deviation of results obtained in three independent experiments. IL: interleukin, TNF: tumor necrosis factor, LED: light-emitting diode, LPS: lipopolysaccharide, RT-PCR: reverse transcription polymerase chain reaction, GAPDH: glyceraldehyde 3-phosphate dehydrogenase. $\star p<0.05$ and $* * * p<0.001$ compared with the control group. 
in LPS treatment compared with control $(\mathrm{p}<0.001)$. The expression of IL-1 $\beta$ (Fig. 3D, 3E) and TNF- $\alpha$ (Fig. 3D, $3 \mathrm{~F})$ protein was also increased, but there was no difference in the expression level and the effect of LED curing light irradiation was not confirmed $(p<0.001)$. In the case of the LED+ group, it was confirmed that mRNA and protein of IL-1 $\beta$ and TNF- $\alpha$ were significantly increased with increasing time $(\mathrm{p}<0.05)$. mRNA and protein expression of IL-1 $\beta$ and TNF- $\alpha$ showed that LED curing light irradiation did not induce inflammatory changes in the inflammation-induced Raw264.7 macrophage cells by LPS, but LED curing light can lead to an inflammatory state in normal Raw264.7 macrophage cells.

\section{Discussion}

The LED curing blue light with a wavelength of $440 \sim$ $490 \mathrm{~nm}$ set to the conditions applied in the dental clinics was irradiated in normal and inflammation-induced Raw264.7 macrophages. The effect of LED curing light was analyzed by MTT assay and microscopic observation. Our results show that LED curing light does not affect cell viability and morphology of Raw264.7 macrophages. This was similar to the results of Jeong and Jeong ${ }^{9)}$, but it differs from other reports in which the degree of light irradiation was significantly higher than in clinical practice ${ }^{17,18)}$. Therefore, viability and proliferation of cells may be affected by irradiation time and irradiation dose of LED curing light ${ }^{19)}$. In addition, the effect of LED light on various cell lines was negative as the irradiation amount was increased and the irradiation time was longer ${ }^{1)}$. It has been reported that long-term irradiation to lower intensity has less cytotoxicity than short-term irradiation to higher intensity $^{5}$. Although the irradiation time and dose of the LED curing light practically applied in dental clinics did not affect the cell viability and morphology of Raw264.7 macrophage, it induced overexpression of $\mathrm{NO}$ and $\mathrm{PGE}_{2}$ (pro-inflammatory mediators) and IL-1 $\beta$ and TNF- $\alpha$ (pro-inflammatory cytokines). In other words, LED curing light irradiation in normal Raw264.7 cells did not change the cell viability and morphology, but it showed that it is possible to induce an inflammatory state with increasing time. This is because LED curing light absorbed by mitochondria and porphyrin-containing enzymes induces mitochondrial dysfunction, excessive oxidative stress, heat generation and negatively affects cells. Hence, cells irradiated with LED curing light cause DNA damage, a decrease of cell viability and proliferation, inhibition of cell division and inflammation ${ }^{5,19,20)}$. Therefore, LED curing light irradiation needs to be limited to an appropriate dose as supported by another study in MDPC-23 cells ${ }^{9}$. On the other hand, several studies have shown that LED irradiation has a positive effect such as photodynamic therapy (PDT) on wound healing and oral tissue inflammatory response ${ }^{9,16,21-23)}$. Irradiation of LED curing light in inflammation-induced MDPC-23 cell, an odontoblastic cell by LPS, has been reported to have a similar effect as PDT $^{9}$. However, the irradiation of the LED curing light in Raw264.7 macrophages treated with the same conditions as Jeong and Jeong ${ }^{9)}$ and induced inflammation by LPS did not affect the inflammatory reaction and no effect like PDT was observed. Therefore, the irradiation of LED curing light in RAW264.7 macrophages may induce excessive inflammatory reaction and damage in oral tissues. It is therefore necessary to limit the long-term irradiation which is inappropriate when applying LED curing light to polymerize composite resin in dental clinics.

\section{Notes}

\section{Conflict of interest}

No potential conflict of interest relevant to this article was reported.

\section{Ethical approval}

This article is not necessary for IRB screening because it is an experimental paper using commercially available cells.

\section{ORCID}

Moon-Jin Jeong, https://orcid.org/0000-0002-5547-898X

Ki-Sung Kil, https://orcid.org/0000-0003-0434-8875

Myoung-Hwa Lee, https://orcid.org/0000-0003-2291-5589

Seung-Yeon Lee, https://orcid.org/0000-0003-3485-7427

Hye-Jin Lee, https://orcid.org/0000-0002-0187-4063 
Do-Seon Lim, https://orcid.org/0000-0003-4602-3323

Soon-Jeong Jeong, https://orcid.org/0000-0002-8959-4663

\section{Acknowledgements}

This study was supported by research fund from Chosun University, 2018.

\section{References}

1. Wataha JC, Lewis JB, Lockwood PE, Noda M, Messer RL, Hsu S: Response of THP-1 monocytes to blue light from dental curing lights. J Oral Rehabil 35: 105-110, 2008. https://doi.org/10.1111/j.1365-2842.2007.01806.x

2. Wataha JC, Lockwood PE, Bouillaguet S, Noda M: In vitro biological response to core and flowable dental restorative materials. Dent Mater 19: 25-31, 2003. https://doi.org/10.1016/S0109-5641(02)00012-X

3. Nakamura S, Mukai T, Senoh M: Candela-class highbrightness InGaN/AlGaN double-heterostructure blue-lightemitting diodes. Appl Phys Lett 64: 1687-1689, 1994.

4. Kurachi C, Tuboy AM, Magalhães DV, Bagnato VS: Hardness evaluation of a dental composite polymerized with experimental LED-based devices. Dent Mater 17: 309-315, 2001. https://doi.org/10.1016/S0109-5641(00)00088-9

5. Ergun G, Egilmez F, Cekic-Nagas I: The effect of light curing units and modes on cytotoxicity of resin-core systems. Med Oral Patol Oral Cir Bucal 15: e962-e968, 2010. https://doi.org/doi:10.4317/medoral.15.e962

6. Thind BS, Stirrups DR, Lloyd CH: A comparison of tungsten-quartz-halogen, plasma arc and light-emitting diode light sources for the polymerization of an orthodontic adhesive. Eur J Orthod 28: 78-82, 2006. https://doi.org/10.1093/ejo/cji076

7. Wataha JC, Lockwood PE, Lewis JB, Rueggeberg FA, Messer RL: Biological effects of blue light from dental curing units. Dent Mater 20: 150-157, 2004. https://doi.org/10.1016/S0109-5641(03)00086-1

8. Lockwood DB, Wataha JC, Lewis JB, Tseng WY, Messer RL, Hsu SD: Blue light generates reactive oxygen species (ROS) differentially in tumor vs. normal epithelial cells. Dent Mater 21: 683-688, 2005. https://doi.org/10.1016/j.dental.2004.07.022

9. Jeong MJ, Jeong SJ: Biological effects of light-emitting diodes curing unit on MDPC-23 cells and lipopolysaccharide stimulated MDPC-23 cells. J Dent Hyg Sci 19: 39-47, 2019. https://doi.org/10.17135/jdhs.2019.19.1.39

10. Klapproth JM, Sasaki M: Bacterial induction of proinflammatory cytokines in inflammatory bowel disease. Inflamm Bowel Dis 16: 2173-2179, 2010. https://doi.org/10.1002/ibd.21332

11. Striz I, Brabcova E, Kolesar L, Sekerkova A: Cytokine networking of innate immunity cells: a potential target of therapy. Clin Sci (Lond) 126: 593-612, 2014. https://doi.org/10.1042/CS20130497

12. Moncada S, Higgs A: The L-arginine-nitric oxide pathway. N Engl J Med 329: 2002-2012, 1993. https://doi.org/10.1056/NEJM199312303292706

13. Slots J, Gibbons RJ: Attachment of Bacteroides melaninogenicus subsp. asaccharolyticus to oral surfaces and its possible role in colonization of the mouth and of periodontal pockets. Infect Immun 19: 254-264, 1978.

14. Birkedal-Hansen H, Taylor RE, Zambon JJ, Barwa PK, Neiders ME: Characterization of collagenolytic activity from strains of Bacteroides gingivalis. J Periodontal Res 23: 258-264, 1988. https://doi.org/10.1111/j.1600-0765.1988.tb01369.x

15. Lee HO, Park JY: Antibacterial effect and cytotoxicity of desensitizer containing antimicrobial. J Dent Hyg Sci 15: 238-245, 2015. https://doi.org/10.17135/jdhs.2015.15.2.238

16. Jeong SJ, Choi BD, Lee HY, et al.: $660 \mathrm{~nm}$ red LED induces secretory leukocyte protease inhibitor (SLPI) in lipopolysaccharide-stimulated RAW264.7 cell. J Nanosci Nanotechnol 15: 5610-5616, 2015. https://doi.org/10.1166/jnn.2015.10465

17. Yalcin M, Kenar H, Dayi B, Sisman R, Karaoz E: The effect of light curing units on proliferation and senescence of human dental pulp mesenchymal stem cells. Int J Dent Sci Res 4: 10-16, 2016.

18. Liebmann J, Born M, Kolb-Bachofen V: Blue-light irradiation regulates proliferation and differentiation in human skin cells. J Invest Dermatol 130: 259-269, 2010. https://doi.org/10.1038/jid.2009.194

19. Liebmann J, Born M, Kolb-Bachofen V: Blue-light irradiation regulates proliferation and differentiation in human skin cells. J Invest Dermatol 130: 259-269, 2010. https://doi.org/10.1038/jid.2009.194 
20. Gorgidze LA, Oshemkova SA, Vorobjev IA: Blue light inhibits mitosis in tissue culture cells. Biosci Rep 18: 215-224, 1998. https://doi.org/10.1023/A:1020104914726

21. Geminiani A, Caton JG, Romanos GE: Temperature change during non-contact diode laser irradiation of implant surfaces. Lasers Med Sci 27: 339-342, 2012. https://doi.org/10.1007/s10103-010-0876-8

22. Cho KW, Lee SY, Chang BS, Um HS, Lee JK: The effect of photodynamic therapy on Aggregatibacter actinomyce- temcomitans attached to surface-modified titanium. J Periodontal Implant Sci 45: 38-45, 2015.

https://doi.org/10.5051/jpis.2015.45.2.38

23. Bjordal JM, Couppé C, Chow RT, Tunér J, Ljunggren EA: A systematic review of low level laser therapy with location-specific doses for pain from chronic joint disorders. Aust J Physiother 49: 107-116, 2003.

https://doi.org/10.1016/S0004-9514(14)60127-6 